Journal of Economics and Behavioral Studies

Vol. 6, No. 6, pp. 452-465, June 2014 (ISSN: 2220-6140)

\title{
Household Debts-and Macroeconomic factors Nexus in the United States: A Cointegration and Vector Error Correction Approach
}

\author{
Ntebogang Dinah Moroke \\ North West University, South Africa \\ Ntebo.Moroke@nwu.ac.za
}

\begin{abstract}
This study applies cointegration and error correction approaches to determine the effect of macroeconomic determinants on household debt in the United States of America. Cointegration analysis provides an effective framework used for estimating and modelling relationships from time series data. Short-run and long-run cointegration models explaining the relationships between the US household debt and related macroeconomic factors are estimated. The data used covers a period of 1990 Q1 to 2013 Q1 and is sourced from the electronic data delivery system of the OECD, USA Federal Housing Finance Agency and the USA Department of the Treasury among others. SAS 9.3 version was used to obtain the results. The sample and variables were meritorious according to KMO and Cronbach's alpha. Unit root test results provided enough evidence to conclude that the series were stationary after first differencing. Further data analysis was carried out with the first lag chosen by the AIC and SBC. Three cointegrating vectors were identified and were later standardised to correctly provide parameter estimates of the vector error correction model of household debts. The model revealed some short and long-run relationships. Revealed by the model is that $1.5 \%$ of long-run equilibrium was corrected per quarter. The results of the current study are crucial to households and policy makers. Researchers may also refer to these results.
\end{abstract}

Keywords: Cointegration, Vector Error Correction Model, Household Debts, United States, Macroeconomic variables

\section{Introduction}

A trended or simply non stationary time series data can be regarded as potentially a major problem for empirical econometrics. According to literature, trends, either stochastic or deterministic, may cause spurious regressions and difficulties in interpreting student t-values and other statistics. Also goodness of fit measures become 'too high' and consequently makes regression results rather hard to evaluate. As research indicates, most macroeconomic time-series are subject to some type of a trend and a remedy such as differencing of the series until stationarity is achieved has been suggested. Nevertheless, some researchers proved that 'differencing' may result in a loss of some valuable long-run information in the data. The tight linkage between cointegration and the error correction model (ECM) curtails from the Granger representation theorem. As the theorem states, two or more integrated time-series that are cointegrated have an error correction representation, and two or more time-series that are error correcting are also cointegrated. In essence, these two concepts are isomorphic, as one implies the other. They have been introduced with the hope of avoiding spurious regression results (Lauridsen, 1998). Granger first introduced the concept of 'cointegration' in the early 1980swith a view of avoiding information loss in the data. This concept was later applied by Engle and Granger (1987) who provided a firm theoretical base for representation, testing, estimation and modelling of cointegrated nonstationary time-series variables. Since then, a substantive number of researches on cointegration and related fields were conducted. According to Granger and Weiss (1983), cointegration analysis allows nonstationary data to be used so as to avoid spurious results. This also provides researchers an effective formal framework for testing and estimating long-run equations from actual time series data. Short-run ECM is also suggested in the literature to help correct for long-run relationships. Phillips (1954) introduced the ECM, and Sargan (1964) applied it in economics. An observation is that the application of ECM by Davidson et al. (1978) has been playing an important role in the dynamics of both short-run and long-run adjustment processes. The cointegration and ECM takes account of the dynamics adjustment to steady state targets by including in the short term dynamics, a measure of how far from equilibrium the variables were at the start of the period. 
Given the number of the determinants of household debts used in this study, the vector error correction model (VECM) which employs cointegration is used in the analysis of the model specified for this study. One important prerequisite for the VECM estimation is to determine the characteristics of time series variables in the model, as to whether they are stationary or nonstationary. As defined by Obayelu and Salau (2010), the VECM is a restricted vector autoregression (VAR) designed for use with non stationary variables that are known to be cointegrated. These authors further state that the specification of the VECM restricts the long-run performance of endogenous variables to converge to their cointegrating relationships while allowing for short-run adjustment dynamics. Literature suggests the application of these models to time series variables that are non stationary individually but linked by long-run relationships. The VECM assumes that these variables follow a linear adjustment process towards their long-run equilibrium. The use of the VECM is facilitated when variables are first differenced stationary and cointegrated (Hendry \& Juselius, 2000). It is therefore imperative to determine the stationarity of the series as it ascertains the order of integration. This also helps in determining the number of times a variable has to be differenced to make it stationary. Cointegrationis a restriction on a dynamic model. It is inherently multivariate since a single time series cannot be cointegrated.

Objectives of the study: One goal of the current study is to apply the Johansen's VECM in formulating model of quarterly household debts using the US data. Another goal is to examine the dynamic relations between the US household debts and some of the related macroeconomic determinants. As such, this paper adds to the existing empirical literature on household debts and the application of cointegration and the VECM. The US is chosen as this is a country where the 2007-2009 financial crises were born. As literature reports, this crisis affected most of the economies and has caused lots of households to enter into debts. Again, most of the countries especially in Africa depend on this country for trade. The findings of this study may be of help to economic policy makers in the country as they would know what to emphasise on in respect of household indebtedness. The findings may also help in bridging a gap in literature on the subject. The recommendations made by this study may help prevent further financial crises and thus household indebtedness. To achieve the objectives, the study applies the frameworks of Johansen (1991) cointegration and the VECM in order to estimate both short and long-run household debts. Thus this helps in determining:

- Whether any long term association is there between household debts and identified determinants.

- Whether any shot term association is there between household debts and identified determinants.

\section{Literature Review}

A question of whether relationship between household debt and macroeconomic variables exist has been investigated for few countries. Therefore, it is rare to find studies on household debt prior 1990s.Conflicting results were reported in literature with respect to few of these studies. To an extent, the results reflect that different number of methods was used in these studies for empirical investigation. Some of the methods used are not relevant with the variables in question and the sample sizes used. In this section few of the studies on household debts are reviewed. Not all of these studies employed econometric methods though. The study by Kim (2011) used the vector autoregression (VAR) framework to investigate the impact of household debt on aggregate performance in the United States of America (USA). In this study the VAR analysis capturing the transitory feedback effects observed a bidirectional positive feedback process between aggregate income and debt was constructed. The VECM results showed negative long-run relationships between household debt and GDP. This empirical model was also extended to include investment and corporate debt as independent variables. The results of this study were found to be in contrast with the results of empirical model without corporate sector variables. Though the study used GDP as a determinant of household debt in USA, it did not cater for the problem of unit root in the series hence the formulation of the VAR model. To guard again spurious regression results, the current study uses cointegration and standardised VAR approaches for construction of the model showing relationships. Several household debt determinants according to literature and economic theories are used to help construct this model.

Laina (2011) investigated the dynamic effects of total debt to GDP. The methodology used in the said study was based on time-series regression analysis, in which a structural VAR model was estimated. Granger causality tests were used to study the dynamic interactions, impulse response functions and forecast error variance decompositions. The study collected quarterly USA GDP and real total debt growth data for period 1959 to 2010. The findings of this study revealed that real total debt growth affects real GDP growth, but no feedback from real GDP growth to real total debt growth was found. The 
results showed that the response of real GDP growth to a shock in real total debt growth seemed to be transitory, with the level effect being persistent. In both cases the effect was found to be in the same direction. This study considered a bivariate analysis hence the use of Granger causality tests. However, it should be noted that cointegration between the variables and the testing of unit root was not looked at; hence the VAR model was estimated. Therefore, the results of this study could be spurious. The current study intends to use the VECM to guard against the problems mentioned. This method also allows a simultaneous inclusion of multiple variables and can differentiate between the dependent and independent variables. This will help in achieving the objectives set for the study.

Barnes and Young (2003) employed a calibrated partial equilibrium overlapping generation (OLG) model to explain household debt in terms of a consumption-income and housing-finance motivations of the US. Their findings show that the substantial rise of household debt in the 1990s can be well explained by real interest rate, income growth expectations, demographic changes, and the removal of credit constraint. Tudela and Young (2005) also used the OLG model to analyse the household debt in UK. They claimed that changes in interest rates, house prices, preferences, and retirement income affect household debt. Jacobsen (2004) employed dynamic model and quarterly data from 1994 Q1 to 2004 Q1 in Norway to estimate the effects of various factors on household debt. They also claimed that many factors such as the housing stock, interest rates, the number of house sales, the wage income, the housing prices, the unemployment rate, and the number of students influence household debt in this country. Thaicharoen et al. (2004) who also used the OLG model in their study report that low interest rates, demographics, and declining borrowing constraints contribute to debt in Thai households. Also reported is that current debt levels in Thailand do not pose a threat to financial stability and the macro economy. In his study using the same method, Crook (2003) did a comparative study of the effects of household debt across a several countries. His study reported that the debt holding by age follows the life cycle pattern in all countries observed. Further findings showed that there are considerable variations in the determinants of desired levels of debt and that there is intra and inter-national variation in the marginal effects of household debt.

An important point should be noted that there are limitations in these previous studies. Firstly, basic descriptive statistics were employed in some of these studies to describe the relationship between household indebtedness and the influential factors. Second, the OLG method by Barnes and Young (2003), Tudela and Young (2005), Jacobsen (2004), Crook (2003) and Thaicharoen et al. (2004) fail to take into account the methods which the current study intends to adopt for the analysis. Problems of unit root in time series variables which gives rise to spurious regression results are not taken care of. We intend to use cointegation and the VECM frameworks in estimating the model describing the short-run and longrun relationships from the US household debt data and related macroeconomic factors. Moreover, multivariate causality tests are employed to confirm causal relationships between the variables.

\section{Methodology}

Data: The empirical analysis uses quarterly data that covers the period 1990 Q1-2013 Q1. This sample period was selected because it constitutes the 2007-2009 US financial crisis. Again the period provides more observations that may help in avoiding non normality of the residuals and the effective application of the methods chosen for data analysis are catered for. The data are mainly sourced from the electronic data delivery system of the OECD such as USA Federal Housing Finance Agency and the USA Department of Treasury among others. Analysis of data is done using the Statistical Software Analysis (SAS) version 9.3. A number of theories seeking to explain household indebtedness have been suggested in literature. Two of these theories are used as a motivation for choosing the determinants of household debts in this study. These theories date back to Keynes (1936) who thought of the subject in the form of the absolute income hypothesis (AIH), with Modigliani (1986) following it up with the life cycle hypothesis (LCH) in 1954. Later Friedman (1957) devised it with the permanent income hypothesis (PIH). These theories are considered in this study to suggest the independent variables as determinants of household debt.

Also as literature explains, the household debt level is jointly determined by supply and demand, that is, the households' decision to take on debt and the availability of funding (Meng et al., 2011). Nevertheless, both sides are ultimately determined by macroeconomic variables, consequently the determinants of household debt must lie in these macroeconomic factors. Through analysing factors affecting borrowing and/or lending, following Meng et al. (2011) approach, this study obtain the following potential determinants of household debt transformed using logs; house prices (HP), consumer prices (CP), household income (INC), interest rates (IR), gross domestic product (GDP), household consumption (HC), 
household savings (HS), unemployment rates (UR) and exchange rates (ER) to help us portray the behaviour of households towards debt taking. The analysis uses household debts ratio (HHD) as a dependent variable. Note that nominal values on the constructs obtained from the sources mentioned were converted into real values by deflating them with the CPI. A brief motivation for including each of these variables is given below.

House prices (HP): House price plays a significant role in determining the rise and fall of household indebtedness. The PIH and study by Subhanij (2007) postulate that rise in house prices could encourage households to consume more and build up debt by betting on higher expected future incomes. Debelle (2004) emphasises that the higher house prices are relative to household income, the more debt households have to incur to buy housing. The inclusion of this variable helps in capturing both the wealth effect, from a change in asset price.

Consumer price (CP): As inflation decreases, household borrowing costs are also reduced allowing a substantial number of households to borrow and to increase the average level of debt per borrowing household. Subsequently, lower inflationary rates cause the real value of the debt not to be eroded as fast as in the past. Households may in future be compelled to service their debt and lower their desired consumption. Consumer prices are used as proxy of the inflation rate and are included to capture the effect of speed at which the debt-to-income ratio erodes. This also helps in investigating if households are inclined to go in for debt when the prices of goods and services fluctuate.

Unemployment rate (UR) and household income (INC): The largest and most significant negative shock to household income is unemployment according to Debelle (2004). The author reported that greater household indebtedness and higher debt service levels will heighten the sensitivity of households to a rise in unemployment, amplifying the effect of negative shock to the economy. Debelle (2004) cautions that households with debt will find it more difficult to maintain their mortgage payments through a period of unemployment, and hence will be more likely to default. Income is included in the model to help ascertain if an increase in the debt-to-income-ratio is due to lack of money in the households.

Interest rate (IR): A long period of low interest rate may be an incentive for households to borrow. For instance, when the interest rate is halved, households can double their take-out loan and still face the same servicing cost. According to Kearns and Woods (2006), rise in interest rates may cause substantial repayment burdens for significant number of newly mortgaged households. They further advised that continuous mortgage growth lending may lead to a higher rate of mortgage arrears among households, especially if the lending criteria are relaxed and households accept the higher repayment burdens. Interest rates in this study help to capture the effect of changes in financial regulations and innovations.

Gross Domestic Product (GDP), household consumption expenditure (HC) and unemployment rate (UR): As GDP growth rises coupled with a period of low unemployment, higher consumer confidence and rising consumer spending may be expected. As a result, private consumption expenditure may expand accordingly, implying that households could increasingly take out loans to finance their consumption. GDP variance is included in the model to capture the effect of output volatility. This also measures how the increase in economic growth of the country could possibly affect household debt. As dictated by the LCH theory, the more households spend, the more their income will decrease and the more they will opt for more debt.

Household savings (HS): Personal savings as defined by Clark and Daniel (2006) is the amount by which the current income of households exceeds their current expenditures. On the other hand, Prinsloo (2002) regards this factor as current income after the payment of direct taxes is not consumed or transferred as part of household current expenditure. According to Prinsloo, dissaving occurs when current expenditures exceed current income. Increases in commitments of households decrease their savings. An integration of this variable into the model helps in investigating whether increases in household debt is due to lack of saving behaviour among households as theory suggests. Keynesian theory suggests that interest rate is inversely related to household consumption and positively related to household savings. Less interest rate lures households into increasing their consumption and saving, implying more debt accumulation according to Mason and Jayadev (2012). 
Methodology: Using Johansen's VECM, this article examines the dynamic relations between the US household debts and related macroeconomic variables. Although one can still use Engle and Granger's (1987) two-step ECM in a multivariate context, VECM yields more efficient estimators of cointegrating vectors. The motivation is that a VECM is a full information maximum likelihood estimation model and it allows for testing for cointegration in a whole system of equations in one step and without requiring a specific variable to be normalized (Maysami and Koh, 2000). This also allows one to avoid carrying over the errors from the first step into the second, as would be the case if Engle-Granger's methodology is used. This approach also has the advantage of not requiring priori assumptions of endogenity or exogenity of the variables. For this study, the basic model is a ten equation VAR on quarterly data for the period 1990 Q1 to 2013 Q1. The general form of the VAR model is;

$$
\ln Y_{t}=\pi_{l} H H D_{t-l}+\ldots+\pi_{10} U R_{t-10}+\varepsilon_{t}
$$

Expressed in regression form with expected signs according to economic theory the model becomes;

$$
\ln Y_{t}=\ln H H D_{t}+\underbrace{\beta_{1} \ln H P_{t}}_{+}+\underbrace{\beta_{2} \ln C P I_{t}}_{-}+\underbrace{\beta_{3} \ln I N C_{t}}_{-}+\underbrace{\beta_{4} \ln I R_{t}}_{-}+\underbrace{\beta_{5} \ln G D P_{t}}_{+}+\underbrace{\beta_{6} \ln H C_{t}}_{+}+\underbrace{\beta_{7} \ln H S_{t}}_{-}+\underbrace{\beta_{8} \ln E R_{t}}_{-}+\underbrace{\beta_{9} \ln U R_{t}}_{-}+\mu_{t}
$$

Where $\varepsilon, \mu=$ error term and $\pi, \beta^{\prime} s=$ coefficients of the independent variables described in the previous sections.

Data analysis procedure: Preliminary data analysis is done with respect to the sample used. Bearing in mind that this study uses multivariate techniques, it is required that the sample selected be as adequate and reliable as possible. Also since the objective is to investigate the long and short run relationships between the variables, these chosen household debt determinants are expected to be correlated to a certain degree, but high collinearity degree must be avoided. It is therefore imperative to make sure prior the actual analysis that these basic requirements are satisfied. The Keiser Meyer Olkin (KMO) is used in this study to determine whether the chosen sample is acceptable or not. This measure is calculated using the following formula:

$$
\begin{aligned}
K M O & =\frac{\sum(\text { correlations })^{2}}{\sum(\text { correlations })^{2}+\sum(\text { partial correlations })^{2}} \\
& =\frac{\underbrace{\sum r_{i j}^{2}}_{i \neq j}}{\underbrace{\sum \sum r_{i j}^{2}}_{i \neq j}+\underbrace{\sum \sum a_{i j}^{2}}_{i \neq j}}
\end{aligned}
$$

Where $r_{i j}=$ Pearson correlation between items $i$ and $j$ and $a_{i j}=$ partial correlation coefficient between items $i$ and $j$. As literature dictates, KMO value should be greater than 0.5 but less than or equal to 1 in order to conclude that the sample is sufficient. Kaiser (1974) suggested measures in the ranges; 1 to 0.9 be characterised as marvellous, 0.8 and 0.89 as meritorious, 0.7 to 0.79 as middling, 0.6 to 0.69 as mediocre, 0.5 to 0.59 as miserable and 0 to $0.49 \mathrm{~s}$ as unacceptable. To evaluate the problem of multicollinearity, this study uses Bartlett's test for sphericity. This test is used to ensure that the degree of correlation between the variables is not significant. The formula below describes the Bartlett's test:

$$
\chi^{2}=-\left[(n-1)-\frac{1}{6}\left(2 p+1+\frac{2}{p}\right)\right]\left[\ln S+p \ln \left(\frac{1}{p}\right) \sum \lambda_{i}\right],
$$

Where $p=$ number of variables, $k=$ number of factors, $\lambda_{i}=i$ th eigenvalue of the sample covariance matrix and the $d f=(p-1)(p-2) / 2$. Churchill (1995) proposed the rejection of the associated hypothesis at least $5 \%$ level of significance. To ensure that the selected variables are true measures of household debt, the study uses Cronbach's alpha. This is a measure of how well set of items measure a single unidimensional latent construct. Byrne, Shavelson, and Muthen (1989) suggest that the variables chosen as predictors must be highly associated with each other and represent a single concept. This suggestion is supported by among others Blaha, Merydith, Wallbrown and Dowd (2001) and Diamantopoulos and Siguaw (2006). Cronbach's alpha ranges from 0 to 1 with values closer to 0 implying 
that the items do not measure the same construct and values closer to 1 are regarded as good measures. The following formula is used to describe Cronbach's $(\alpha)$ :

$$
\alpha=\frac{k r}{1+(k-1)} \text {, }
$$

Where $k$ is the average correlations between the variables and $r$ is the number of variables. Kline (1999) and Cronbach and Shavelson (2004) use the following rules of thumb to describe Cronbach's alpha $\alpha ; \geq$ 0.9 is excellent, $0.8 \leq \alpha<0.9$ is good, $0.7 \leq \alpha<0.8$ is acceptable, $0.6 \leq \alpha<0.7$ is questionable, $0.5 \leq \alpha<0.6$ is poor and if $\alpha<0.5$ is unacceptable.

Stationarity analysis: Many macroeconomic series are nonstationary as affirmed Nelson and Plosser (1982). It is therefore necessary to convert these series to induce stationarity in them. This is also one of the requirements for cointegration analysis. One must establish that the variables possess the same order of integration. According to Kennedy (1996), a variable is integrated of order d, $I(d)$, if it has to be differenced $d$ times to become stationary. In estimating a VECM, this study applies the Augmented DickeyFuller (ADF) test to first examine the stationarity characteristics of the series. KPSS test is used to confirm the stationarity test results. The procedures for using these tests are discussed below:

Augmented Dickey-Fuller (ADF) test: As suggested by Dickey and Fuller (1981), estimation the following regression equation is used for stationarity testing:

$$
\Delta Y_{t}=\alpha+\beta Y_{t-1}+\sum_{i=1}^{k} \phi_{i} \Delta Y_{t-i}+\varepsilon_{t}
$$

With $\Delta$ representing the first difference operator; $t$ is the time drift; $k$ represents the number of lags used and $\varepsilon$ is the error term; $\alpha$ 's and $\beta$ 's are the model bounds. The ADF test includes a constant and deterministic trend. For the decision rule, assuming that the series $\left\{Y_{t} t^{T}=1\right\}$ follows the AR ( $p$ ) process, Hamilton (1990) shows that the rejection or acceptance of the null hypothesis of a unit root is based on running the regression:

$$
Z_{t}=\mu+\left(\phi_{1}-1\right) Y_{t-1}+\sum_{j=1}^{p-1} C_{j} Z_{t-j}+\varepsilon_{t}
$$

Where $Z_{t-j}=Y_{t-j}-Y_{t-j-1}$ for $\mathrm{j}=0,1,2, \ldots, p-1$ and $\varepsilon_{t}$ is a white noise process. The ADF test statistic is given as;

$$
\hat{\tau}_{A D F}=\frac{\hat{\phi}_{1}-1}{\operatorname{se}\left(\hat{\phi}_{1}\right)},
$$

$s e(\phi-1)$ Represents the standard error of $\phi-1$. The null hypothesis of a unit root $H_{o}: \phi_{1}=1$ is rejected $\wedge$

if $\tau_{A D F}$ is less than the appropriate critical value at some level of significance.

Kwiatkowski, Phillips, Schmidt and Shin (KPSS) test: Kwiatkowski et al. (1992) suggested a test that makes it possible for the researcher to confirm whether the series have a deterministic trend versus the stochastic trend. KPSS test is used in this study to confirm the decision made by the ADF tests. The KPSS test statistic is given as:

$$
K P S S=n^{-2} \sum_{t=1}^{n} \frac{S_{t}}{\hat{\sigma}^{2}}
$$

Where $S_{t}=\sum_{i=1}^{t} e_{i}$ and $\hat{\sigma}^{2}$ is the estimate of the long-run variance of the residuals. The study rejects the null hypothesis if the KPSS exceeds the critical value providing evidence that the series wanders from its mean. First order of differencing is applied to induce stationarity in the variables. A lag of up to four is included to correct for autocorrelation since the data are collected on a quarterly basis. If the variables are stationary and integrated of I(1), stationarity condition is achieved. Provided these conditions are 
satisfied, the analysis is continued by determining the cointegration relationship between the variables and this procedure is reviewed in the next section.

The Johansen cointegration test: In order to choose appropriate lag length, this study uses the multivariate forms of the Akaike information criterion (AIC) and Schwartz Bayesian criterion (SBC) also as suggested by (Verbeek, 2004). These information criteria ensure that residuals are Gaussian and help in choosing the model with small lags. Brooks (2008) suggested that if these information criteria provide conflicting results, the one which produces white noise residual and most economically interpretable results should be chosen. These criteria are estimated using the following equations:

$$
\begin{aligned}
& A I C-2\left(\frac{l}{n}\right)+\left(\frac{k}{n}\right) \\
& S B C-2\left(\frac{l}{n}\right)+k \frac{\log (n)}{n}
\end{aligned}
$$

Where $l$ is the log of the likelihood function, $k$ is the number of parameters in the model, $n$ is the number of observations. The AIC and SBC as model selection criteria are developed for maximum likelihood estimation techniques. To minimize the AIC and SBC, one should also minimize the natural logarithm of the residual sum of squares adjusted for $n$ sample size and the number of $k$ parameters included.

This study adopts Johansen and Juselius (1990) multivariate cointegration framework to determine the number of cointegrating vectors. The Maximum Eigenvalue and the Trace test are used to determine these vectors. These test statistics test the null hypothesis of $r$ cointegrating relationships $\left(H_{0}: \lambda_{i}=0\right.$ for $i=r+1, \ldots, k$ ) versus the alternative of $r+1$ cointegrating relations, $H_{a}: \lambda_{i} \neq 0$ for $r=0,1,2 \ldots n-1$. To cater for multivariate analyses, Fountis and Dickey (1989) suggested an examination of eigenvalues following the four steps below:

Step 1: Fit linear multivariate time series as:

$$
\Rightarrow \quad X_{t}=\Phi_{1} X_{t-1}+\Phi_{2} X_{t-2}+\ldots+\Phi_{p} X_{t-p} \text {. }
$$

Step 2: Compute the largest eigenvalue, $\lambda_{\max }$, based on the characteristic equation;

$$
\left|\lambda^{p} \mathrm{I}-\Phi_{1} \lambda^{p-1}-\Phi_{p} \lambda^{p-2}-\ldots-\Phi_{p}\right|=0, I=p \times p \text { Matrix. }
$$

Step 3: Test of the null hypothesis of unit root is based on the following test statistic;

$$
\begin{aligned}
& \hat{\tau}_{\text {mfd }}=N\left(\lambda_{\max }-1\right), \\
& \lambda_{\text {max }} \text { is calculated on step } 2 .
\end{aligned}
$$

Step 4: At the 0.05 significance level, obtain the critical value from the table. Reject $H_{0}$ if $\hat{\tau}_{m f d}>$ critical value or alternatively if the observed probability is less than the level of significance. The following are the Johansen trace and maximum eigenvalues formulae also calculated through these four steps:

$$
\begin{aligned}
& J_{\text {Trace }}=-N \sum_{i=r+1}^{n} \ln \left(1-\hat{\lambda}_{\text {max }}\right) \\
& J_{\text {Max }}=-N \ln \left(1-\hat{\lambda}_{\text {max }}\right)
\end{aligned}
$$

The critical values are found in the Johansen and Juselius (1990) tables. The null hypotheses for these statistics are rejected if the observed values are greater than the critical values. This will imply the presence of cointegration among the variables and a long run relationship as suggested by Sjö (2008). Detailed tables of these critical values are provided in Osterwald-Lenum (1992).It is important to note that Alexander (2001) highlighted that these two tests can yield different results. However, once 
cointegration relationship has been confirmed, the study proceeds to build a VECM and the procedure is discussed below.

Vector Error Correction Model (VECM): Engle and Granger (1987) reveal that if the series are cointegrated, the problems of spurious regression due to omitted variable bias, autocorrelation and endogeneity are ruled out. Only if the series are cointegrated can one proceed to determine the direction of causality among the variables. For this purpose, various VECMs should be specified. These models may be used for observing the short run properties of the series and may provide very useful insights especially for policy makers. This study applies VECM to evaluate the short run properties of cointegrated series identified and to estimate the speed at which household debt returns to equilibrium due to changes in related determinants (Banerjee et al.,2011) as cited by Moroke and Mavetera (2014). The VECM also reduces or increases the values of parameters of the long run relationships where necessary according to Nwachukwu and Egwaikhide (2007).

Given the presence of $r \geq 3$ cointegrating vectors, [1] may be expressed in VECM form as follows; $\Delta \ln Y_{t}=\Gamma \nabla \ln Y_{t-l}+\Pi \ln Y_{t-k}, k=1,2, \ldots, 10$

Where $\nabla Y=\Delta Y_{t}, \ldots, \Delta X_{t \cdot k+1}$. A simplified form expressing all the variables in a system we have the following set of equations:

$$
\begin{aligned}
& \Delta \ln H H D_{t}=\alpha_{1}+\sum_{i=1}^{p}{ }^{1} \eta_{i} \Delta \ln H H D_{t-i}+\sum_{i=1}^{p}{ }^{1} \beta_{i} \Delta \ln H P_{t-i}+\ldots+\sum_{i=1}^{p}{ }^{1} \varpi_{i} \Delta \ln U R_{t-i}+\psi_{1} E C T_{t-1}+v_{1 t}[18] \\
& \Delta \ln H P_{t}=\alpha_{2}+\sum_{i=1}^{p}{ }^{2} \beta_{i} \Delta \ln H P_{t-i}+\sum_{i=1}^{p}{ }^{2} \eta_{i} \Delta \ln H H D_{t-i}+\ldots+\sum_{i=1}^{p}{ }^{2} \varpi_{i} \Delta \ln U R_{t-i}+\psi_{2} E C T_{t-1}+v_{2 t}[19] \\
& \Delta \ln C P_{t}=\alpha_{3}+\sum_{i=1}^{p}{ }^{3} \phi_{i} \Delta \ln C P_{t-i}+\sum_{i=1}^{p}{ }^{3} \beta_{i} \Delta \ln H P_{t-i}+\ldots+\sum_{i=1}^{p}{ }^{3} \varpi_{i} \Delta \ln U R_{t-i}+\psi_{3} E C T_{t-1}+v_{3 t} \\
& \Delta \ln I N C_{t}=\alpha_{4}+\sum_{i=1}^{p}{ }^{4} \theta_{i} \Delta \ln I N C_{t-i}+\sum_{i=1}^{p}{ }^{4} \phi_{i} \Delta \ln C P_{t-i}+\ldots+\sum_{i=1}^{p}{ }^{4} \varpi_{i} \Delta \ln U R_{t-i}+\psi_{4} E C T_{t-1}+v_{4 t}[21] \\
& \Delta \ln I R_{t}=\alpha_{5}+\sum_{i=1}^{p}{ }^{5} \kappa_{i} \Delta \ln I R_{t-i}+\sum_{i=1}^{p}{ }^{5} \theta_{i} \Delta \ln I N C_{t-i}+\ldots+\sum_{i=1}^{p}{ }^{5} \varpi_{i} \Delta \ln U R_{t-i}+\psi_{5} E C T_{t-1}+v_{5 t}[22] \\
& \Delta \ln G D P_{t}=\alpha_{6}+\sum_{i=1}^{p}{ }^{6} \rho_{i} \Delta \ln G D P_{t-i}+\sum_{i=1}^{p}{ }^{6} \kappa_{i} \Delta \ln I R_{t-i}+\ldots+\sum_{i=1}^{p}{ }^{6} \varpi_{i} \Delta \ln U R_{t-i}+\psi_{6} E C T_{t-1}+v_{6 t} \\
& \Delta \ln H C_{t}=\alpha_{7}+\sum_{i=1}^{p}{ }^{7} \vartheta_{i} \Delta \ln H C_{t-i}+\sum_{i=1}^{p}{ }^{7} \rho_{i} \Delta \ln G D P_{t-i}+\ldots+\sum_{i=1}^{p}{ }^{7} \varpi_{i} \Delta \ln U R_{t-i}+\psi_{7} E C T_{t-1}+v_{7 t}[24] \\
& \Delta \ln H S_{t}=\alpha_{8}+\sum_{i=1}^{p} \gamma_{i} \Delta \ln H S_{t-i}+\sum_{i=1}^{p} \vartheta_{i} \Delta \ln H C_{t-i}+\ldots+\sum_{i=1}^{p} \varpi_{i} \Delta \ln U R_{t-i}+\psi_{1} E C T_{t-1}+v_{8 t} \\
& \Delta \ln E R_{t}=\alpha_{9}+\sum_{i=1}^{p}{ }^{9} \tau_{i} \Delta \ln E R_{t-i}+\sum_{i=1}^{p}{ }^{9} \gamma_{i} \Delta \ln H S_{t-i}+\ldots+\sum_{i=1}{ }^{9} \varpi_{i} \Delta \ln U R_{t-i}+\psi_{9} E C T_{t-1}+v_{9 t} \\
& \Delta \ln U R_{t}=\alpha_{10}+\sum_{i=1}^{p}{ }^{10} \varpi_{i} \Delta \ln U R_{t-i}+\sum_{i=1}^{p}{ }^{10} \gamma_{i} \Delta \ln H S_{t-i}+\ldots+\sum_{i=1}^{p}{ }^{10} \tau_{i} \Delta \ln E R_{t-i}+\psi_{10} E C T_{t-1}+v_{10 t}[27]
\end{aligned}
$$

$\Delta$ Represents the first difference operator, $\ln$ is the natural logarithm, $i=1,2,3, \ldots, 10$, the residuals $v_{i t}$ are assumed to be normally distributed and to follow a white noise process. $E C T_{t-1}$ is the one period lagged error-correction term from the long-run cointegrating relationship. The coefficients of $E C T_{t-1}, \psi_{1}, \ldots, \psi_{10} \quad$ capture the adjustments of $\Delta \ln \beta_{t}, \Delta \ln \phi_{t}, \Delta \ln \theta_{t}, \Delta \ln \kappa_{t}, \Delta \ln \rho_{t}, \Delta \ln \vartheta_{t}, \Delta \ln \gamma_{t}, \Delta \ln \psi_{t}, \Delta \ln \varpi_{t}$ towards $\quad$ the $\quad$ long $\quad$ run equilibrium. Short run causality relationships are tested through the coefficients of each determinant. This study uses a modified Granger causality test proposed by Toda-Yamamoto (1995) to determine the direction of causality between the variables. Toda-Yamamoto causality requires the estimation of an 
augmented VAR model which guarantees the asymptotic distribution of the Wald statistic. The statistic follows a chi-square distribution with $m$ degrees of freedom. The null hypothesis associated with the coefficient of household debt in [18] is given as:

$H_{01}: \eta_{1}=\eta_{2}=\ldots=\eta_{p}=0$ and implies that household debt does not cause exchange rates.

\section{Results and Discussion}

Table 1 gives a summary of results confirming the adequacy of sample and variables used in this study.

Table 1: Sample and variable adequacy

\begin{tabular}{ll}
\hline Measure & Value \\
\hline Cronbach's Alpha & 0.854598 \\
KMO & 0.774 \\
Bartlett's test & $2040.49(\mathrm{DF}=36)$ \\
Determinant & $6.826 \mathrm{E}-011$ \\
\hline
\end{tabular}

Source: Authors own calculation from the US Household debts data KMO: Keiser-Meyer-Olkin

As Table 1 reveals, the variables chosen for this study are true measures of household debt (HHD). This is shown by Cronbach's alpha (0.855) which is good according to Kline (1999) and Cronbach and Shavelson (2004). This implies that the variables chosen for the analysis are unidimensional and this is agreeable with Byrne et al. (1989), Blaha et al. (2001) and Diamantopoulos and Siguaw (2006). The KMO measure is reported to be middling. Based on these findings, the sample selected for this study is adequate and the results can be generalised (Kaiser 1974). As Bartlett's test suggest, multicollinearity is not a serious problem. The critical values of chi square associated with Bartlett's statistic at $5 \%$ significance level and 36 degrees of freedom is 55.758. The null hypothesis that the matrix is an identity is rejected confirming that multicollinearity is not a problem (Churchill, 1995).

An informal inspection of the data series indicates that the variables tend to increase over the sample period. Most of the series appear to be I(1) according to ADF tests. We thus regard these series to be $I$ (1), i.e., they contain a unit root in levels and differencing need to be applied to induce stationarity. According to Engle and Grangers' (1987) theory of cointegration, this treatment implies that linear combination of the variables given in [2] may well be a stationary $I(0)$ process. This may result in the existence of cointegration relationship. As suggested by Gujarati (2010), an important implication is that cointegration rationalises the use of ECM models, and thus the possibility of estimating both short and long run effects on household debts.

Unit root test results: Table 2 and 3 summarise the results of unit root and stationarity tests for the 10 variables included in the model after first differencing.

Table 2: ADF unit root tests

\begin{tabular}{lll}
\hline VARIABLE & ADF & DECISION \\
\hline HHD & $-4.07(0.0098)^{*}$ & Reject the null hypothesis \\
HP & $-6.02(0.0001)^{*}$ & Reject the null hypothesis \\
CPI & $-11.31(0.0001)^{*}$ & Reject the null hypothesis \\
INC & $-6.39(0.0001)^{*}$ & Reject the null hypothesis \\
IR & $-7.36(0.0001)^{*}$ & Reject the null hypothesis \\
GDP & $-4.1790 .0072)^{*}$ & Reject the null hypothesis \\
HC & $-4.39(0.0037)^{*}$ & Reject the null hypothesis \\
HS & $-7.21(0.0001)^{*}$ & Reject the null hypothesis \\
ER & $-8.10(0.0001)^{*}$ & Reject the null hypothesis \\
UR & $-3.38(0.0599)^{* *}$ & Reject the null hypothesis \\
\hline
\end{tabular}

Source: Authors own calculation from Household debts data, US

All variables are in log forms. An asterisk ${ }^{*}$ and ${ }^{* *}$ denote $5 \%$ and $10 \%$ significance levels. Critical values are from Davidson and MacKinnon (1993). 
Table 2: KPSS Stationarity Test

\begin{tabular}{llllll}
\hline Type & Lags & Eta & Prob 10 \% & Prob 5 \% & Prob 1 \% \\
\hline Single Mean & 3 & 0.0946 & 0.3470 & 0.4630 & 0.7390 \\
Trend & 3 & 0.0961 & 0.1190 & 0.1460 & 0.2160 \\
\hline
\end{tabular}

Source: authors own calculation from the US household debts data

The results presented in Table 2 suggest at $5 \%$ significance level that the null hypothesis of a unit root (i.e., nonstationarity) is rejected when the series are in first differences. The observed probabilities (on parenthesis) are also less than the 5\% level of significance except for UR which is significant at $10 \%$. Furthermore, the KPSS also confirms that that the series exhibit stationarity around a deterministic linear time trend.

Cointegration results: Table 3 provides results for minimum information criteria (MINIC) discussed.

Table 3: AIC and SBC

\begin{tabular}{lllllll} 
AIC & -79.229 & & & & \\
SBC & -76.2138 & & & & \\
\hline AIC & & & & & & \\
AR 0 & -58.57668 & -57.37487 & -56.09162 & -54.80699 & -54.2561 & -54.74244 \\
AR 1 & -79.22903 & -78.69282 & -77.96713 & -78.06888 & -79.66333 & -83.08709 \\
AR 2 & -79.69407 & -79.78797 & -79.3084 & -80.81069 & -85.12969 & -101.7298 \\
SBC & & & & & & \\
AR 0 & -58.30435 & -54.69419 & -50.93913 & -47.8864 & -44.94374 & -42.14654 \\
AR 1 & -76.21385 & -73.35538 & -70.5153 & -69.19418 & -67.82545 & -67.4007 \\
AR 2 & -73.89978 & -71.20147 & -68.74987 & -67.77122 & -67.64267 & -69.11102 \\
AR 3 & -70.753 & -68.86906 & -67.51273 & -66.84623 & -68.39117 & \\
\hline
\end{tabular}

AIC: Akaike information criterion, SBC: Schwartz Bayesian criterion, AR: Autoregression, MA: Moving average

Source: Authors own calculation from the US Household debts data

The results reveal that $\mathrm{AIC}$ and $\mathrm{SBC}$ choose the first lag (AR 1) as a default lag. This implies that the analysis is executed with this lag as an optimal lag. Having chosen the lag number, we now proceed with cointegration analysis.

Table 4 gives summary results indicating the order for the Johansen cointegration rank tests and also confirms possibility of long-run relationships between the variables.

Table 4: Cointegration results

\begin{tabular}{|c|c|c|c|c|c|}
\hline $\begin{array}{l}\mathrm{H}_{0}: \\
\text { Rank=r }\end{array}$ & $\begin{array}{l}\mathrm{H}_{1}: \\
\text { Rank>r }\end{array}$ & Trace & $\begin{array}{l}5 \quad \% \\
\text { Critical } \\
\text { Value } \\
\end{array}$ & $\begin{array}{l}\text { Max } \\
\text { eigenvalue }\end{array}$ & $\begin{array}{ll}\mathbf{5} & \% \\
\text { Critical } & \\
\text { Value } & \\
\end{array}$ \\
\hline 0 & 0 & 326.0672 & 232.60 & 105.3766 & 62.81 \\
\hline 1 & 1 & 242.2137 & 192.30 & 88.5401 & 57.12 \\
\hline 2 & 2 & 173.6271 & 155.75 & 63.8624 & 51.42 \\
\hline 3 & 3 & 119.2882 & 123.04 & 44.9380 & 45.28 \\
\hline 4 & 4 & 82.7080 & 93.92 & 26.7583 & 39.37 \\
\hline 5 & 5 & 53.8661 & 68.68 & 22.8977 & 33.46 \\
\hline 6 & 6 & 34.6115 & 47.21 & 14.0998 & 27.07 \\
\hline 7 & 7 & 20.0463 & 29.38 & 7.4046 & 20.97 \\
\hline 8 & 8 & 11.7308 & 15.34 & 5.2918 & 14.07 \\
\hline 9 & 9 & 3.7227 & 3.84 & 0.9877 & 3.76 \\
\hline
\end{tabular}

Source: Authors own calculation from US the Household debts data

The Trace test and the Maximum Eigenvalue are less than the associated critical values from rank 3 . This suggests that the null hypothesis that there is no cointegration between the variables is rejected. The results advocate at least three cointegrating vectors and existence of long run associations between the variables. As stated in Enders (2005) cointegrated variables share the same stochastic trends and so cannot drift too far apart. 
VECM results: Table 5 provides the estimated VECM obtained from one of the cointegration vectors. In estimating this model, necessary diagnostic tests were done to rule out discrepancies.

Table 5: Error correction representation: dependent variable: HHD

\begin{tabular}{|c|c|c|c|c|c|}
\hline Parameter & Estimate & $\begin{array}{l}\text { Standard } \\
\text { Error }\end{array}$ & t Value & $\operatorname{Pr}>|t|$ & Variable \\
\hline \multirow{2}{*}{ CONST1 } & $(-0.396)$ & 1.263 & 0.41 & & 1 \\
\hline & 0.520 & & & 0.681 & \\
\hline \multirow[t]{2}{*}{$\Delta \ln \beta_{\mathrm{t}}$} & $(0.071)$ & 0.033 & -0.50 & $(0.058)$ & $\mathrm{HP}(\mathrm{t})$ \\
\hline & -0.017 & & & 0.619 & \\
\hline$\Delta \ln \phi_{\mathrm{t}}$ & $(-0.016)$ & 0.069 & -0.40 & $(0.834)$ & $\mathrm{CP}(\mathrm{t})$ \\
\hline$\Delta \ln \theta_{t}$ & $\begin{array}{l}-0.028 \\
(-0.026) \\
0.012\end{array}$ & 0.154 & 0.08 & $\begin{array}{l}0.689 \\
(0.875) \\
0.935\end{array}$ & $\operatorname{INC}(\mathrm{t})$ \\
\hline$\Delta \ln \kappa_{\mathrm{t}}$ & $\begin{array}{l}(0.034) \\
-0.011\end{array}$ & 0.014 & -0.79 & $\begin{array}{l}(0.033) * \\
0.430\end{array}$ & $\operatorname{IR}(\mathrm{t})$ \\
\hline$\Delta \ln \rho_{\mathrm{t}}$ & $\begin{array}{l}(0.065) \\
-0.100\end{array}$ & 0.131 & -0.77 & $\begin{array}{l}(0.653) \\
0.445\end{array}$ & $\mathrm{GDP}(\mathrm{t})$ \\
\hline$\Delta \ln \vartheta_{\mathrm{t}}$ & $\begin{array}{l}(-0.018) \\
0.050\end{array}$ & 0.078 & 0.64 & $\begin{array}{l}(0.833) \\
0.525\end{array}$ & $\mathrm{HC}(\mathrm{t})$ \\
\hline$\Delta \ln \gamma_{\mathrm{t}}$ & $\begin{array}{l}(0.022) \\
-0.034\end{array}$ & 0.009 & -3.46 & $\begin{array}{l}(0.041)^{*} \\
0.001^{*}\end{array}$ & $\mathrm{HS}(\mathrm{t})$ \\
\hline$\Delta \ln \psi_{\mathrm{t}}$ & $\begin{array}{l}(-0.050 \\
-0.026\end{array}$ & 0.016 & -1.59 & $\begin{array}{l}(0.007)^{*} \\
0.116\end{array}$ & $E R(t)$ \\
\hline$\Delta \ln \varpi_{\mathrm{t}}$ & $\begin{array}{l}(0.055) \\
-0.020\end{array}$ & 0.011 & -1.88 & $\begin{array}{l}(0.0001)^{*} \\
0.063\end{array}$ & $\mathrm{UR}(\mathrm{t})$ \\
\hline $\mathrm{ECT}_{\mathrm{t}-1}$ & $\begin{array}{l}(0.901) \\
-0.015\end{array}$ & 0.028 & & & $\mathrm{HHD}(\mathrm{t}-1)$ \\
\hline
\end{tabular}

Values on parentheses represented long run parameter estimates, * Significant at $5 \%$ significance Source: Authors own calculation from Household debts data, Unites States

The results presented in Table 5 show that the error correction coefficient has a negative sign. The longrun coefficients have been adjusted just as suggested by Nwachukwu and Egwaikhide (2007). This implies that the series cannot drift too far apart and convergence may be achieved in the long-run. To be specific, the error correction term indicates that deviation from long-run equilibrium value in one quarter is corrected by the size of that coefficient. For the estimated equation, the correction is around 0.015 $(1.5 \%)$. Though in the long-run household debts may be attributed to increased HP and GDP as reported by Subhanij (2007) and Debelle (2004) respectively. The contribution of these determinants is not significant. However, increases in IR according to Kearns and Woods (2006), HS as the LCH dictates, ER and UR as observed by Debelle (2004) may significantly intensify household indebtedness in the US in the long-run. Nevertheless, in the short-run, increased household debts are associated with low HS. Table 6 gives a summary of causality test results between household debt and related determinants.

Table 6: Toda-Yamamoto Causality Test Results

\begin{tabular}{lllll}
\hline $\begin{array}{l}\text { Group } \\
\text { Variables }\end{array}$ & Group 2 Variables & DF & Chi-Square & Pr $>$ ChiSq \\
\hline HHD & HP CP INC IR GDP HC HS ER UR & 9 & 63.60 & $<.0001^{*}$ \\
HP & HHD CP INC IR GDP HC HS ER UR & 9 & 30.35 & $0.0004^{*}$ \\
CP & HHD HP INC IR GDP HC HS ER UR & 9 & 69.67 & $<.0001^{*}$ \\
INC & HHD HP CP IR GDP HC HS ER UR & 9 & 38.57 & $<.0001^{*}$ \\
IR & HHD HP CP INC GDP HC HS ER UR & 9 & 23.10 & $0.0060^{*}$ \\
GDP & HHD HP CP INC IR HC HS ER UR & 9 & 16.52 & 0.0568 \\
HC & HHD HP CP INC IR GDP HS ER UR & 9 & 30.16 & $0.0004^{*}$ \\
HS & HHD HP CP INC IR HC GDP ER UR & 9 & 28.39 & $0.0008^{*}$ \\
ER & HHD HP CP INC IR HC GDP HS UR & 9 & 13.26 & 0.1513 \\
UR & HHD HP CP INC IR HC GDP HS ER & 9 & 60.02 & $<.0001^{*}$ \\
\hline
\end{tabular}

* Significant at $5 \%$ significance

Source: Authors own calculation from the US Household debts data 
Toda-Yamamoto Granger causality results presented in Table 6 indicate a unidirectional causal relationship running from household debts to GDP and UR. A feedback relationship is shown running between household debts and other variables. The observed probabilities associated with the Likelihood Ratio test are compared with $5 \%$ significance level to arrive to this conclusion. Based on these findings, all the independent variables are confirmed not to be weakly exogenous in the system of household debts except GDP and ER. This is in accordance with Harris (1995). At this moment, we confirm that the previously estimated VECM is plausible.

\section{Conclusion}

This study applied cointegration and the VECM approaches to US household debt data and related determinants. Preliminary data analyses were performed to determine the adequacy of the sample and the variables were also checked if they are real measures of household debts. The associated test statistics provided enough evidence to conclude that the sample is adequate. To satisfy stationarity condition and also guard against spurious results, the variables were subjected to log transformation. First differencing was also applied to the series. Unit root tests confirmed that stochastic properties of all the variables were satisfied and all the variables were integrated of I (1) allowing us to use cointegration techniques on these series. At least three cointegrating vectors were found to be present according to AIC and SBC. These vectors were estimated using the VECM and only the first was selected through the help of standard diagnostic tests. The empirical results presented in this paper reveal that rapidly rising US household debt is the result of favourable macroeconomic factors such as IR, ER and UR. The results also revealed that when households are sufficiently optimistic to borrow and investors are confident to lend, household debt surges. However, the robust economic development in this country, that is, growing GDP cause optimistic expectations. The role played by housing market in the rapid growth of the US household debt is also significant. This proves that the US households are in favour of housing venture. This high housing demand drives up house prices and in turn motivates households to invest more on this factor. Empirically, about $1.5 \%$ of correction was made in the long-run every quarter to allow short-run dynamics. The causality results proved that in the short-run, unidirectional causality running from household debt to GDP and ER may be encountered. Feedback relations were found to be running between household debts and the rest of the determinants though.

Recommendations: Based on these findings, the study provides the following policy suggestions for managing household debt:

- The study recommends even harsher policy measures to be legislated that would benefit not only the consumers but also credit suppliers. Reference can be made to the findings of this study when developing policies. Financial suppliers should be closely monitored and perhaps harsh penalties be decreed to those that do not adhere to the law. Policy makers should advice reserve banks to in future think of other ways of assisting consumers other than reducing IR. This determinant was reported to be one of the root causes of financial crises in the US henceforth household indebtedness. Alternatively, interest rate can be used as an effective tool in controlling household debt. This determinant should be used in a timely, comprehensive, and careful manner. The results from cointegration analyses show negative effects of interest rates on household debt in the short-run. This means that this factor can be a useful tool to use currently to stabilize debts. However, the timing of changing interest rates is very important. One of the reasons why the US country experienced the 2007-2009 financial crisis was as a result of the interest cuts by Federal Reserve Bank. The time when household debt starts picking up speed, increased interest rates may be helpful in the slowing down of household debt accumulation. Careful attention should be given especially when household debt reaches its peak. Given the effects of HP on debts in the long-run, this study recommends that the US government should closely monitor HP and should also intervene in the housing market. This may be done by lowering taxes on houses or by providing subsidies on housing purchases.

- $\quad$ This study accurately modelled household debts for SA following the cointegration and the VECM approach. It is therefore further recommended that another study be conducted where other multivariate econometric approach is used in the analysis. The results of these analyses may be compared to those of the current study. Furthermore, it is suggested that other macroeconomic variables affecting household debts not considered be introduced in the VECM and the recommended model. This may help in accurately and fairly marking the most important similarities and differences between the models. The findings may fill a gap to existing literature on this subject and may also help data analysts to better make a choice between the different 
multivariate methods used for modelling economic data. They will also understand that the analysis of household indebtedness is not only limited to univariate or bivariate measures.

\section{References}

Alexander, C. (2001). Market models: A guide to financial data analysis. John Wiley and Sons, Ltd.

Banerjee, A., Dolado, J. J., Galbraith, J. W. \& Hendry, D. (2011). Co-integration, error correction and the econometric analysis of nonstationary data. OUP Catalogue.

Barnes, S. \& Young, G. (2003). The rise in US household debt: assessing its causes and sustainability. Bank of England Working Paper No. 206.

Blaha, J., Merydith, S. J., Wallbrown, F. H. \& Dowd, E. T. (2001). Bringing another perspective to bear on the factor structure of the MMPI-2. Measurement and Evaluation in counselling and development, $33,234-243$.

Brooks, C. (2008). Introductory econometrics for finance (2.ed. reprinted. Ed). Cambridge University Press, Cambridge.

Byrne, B. M., Shavelson, R. J. \& Muthén, B. (1989). Testing for the equivalence of factor covariance and mean structures: The issue of partial measurement invariance. Psychological Bulletin, 105(3), 456-466.

Churchill, G. A. (1995). Marketing Research: Methodological Foundations, Dryden Press.

Clark, A. E. \& Daniel, T. (2006). Forecasting South African house prices. Investment Analyst Journal, 64, 27-33.

Cronbach, L. J. \& Shavelson, R. J. (2004). My current thought on coefficient alpha and successor procedures. Educational and Psychological Measure, 64, 391-418.

Crook, J. (2003). The Demand and supply for household debt: a cross country comparison. Credit Research Centre Working Paper, No. 1.

Davidson, J. E. H., David, F., Hendry, F., Srba, L. \& Yeo, S. (1978). Econometric modelling of the aggregate time series relationship between consumers' expenditure and income in the United Kingdom. Economic Journal, 88, 661-692.

Davidson, R. \& MacKinnon, J. G. (1993). Estimation and inference in econometrics, New York, Oxford University Press.

Debelle, G. (2004). Household debt and macro economy. BIS Quarterly Review, March, 51-64, http://www.bis.org/publ/qtrpdf/r_qt0403e.pdf.

Diamantopoulos, A. \& Siguaw, J. A. (2006). Formative vs. Reflective Indicators in Measure Development: Does the Choice of Indicators Matter? British Journal of Management, 17, 263-282.

Dickey, D. A. \& Fuller, W. A. (1981). Likelihood ratio statistics for autoregressive time series with a unit root. Econometrica, 49, 1057-1072.

Enders, W. (2005). Applied Econometric Time Series. USA: John Wiley and Sons Ltd.

Engle, R. \& Granger, C. W. J. (1987). Cointegration and Error Correction Estimates: Representation, Estimation and Testing. Econometrica, LV, 251-276.

Fountis, N. G. \& Dickey, D. A. (1989). Testing for a unit root non stationarity in multivariate autoregressive time series. Annals of Statistics, 17, 419-428.

Friedman, M. (1957). A Theory of the Consumption Function. New Jersey: Princeton University Press.

Granger, C. W. J. \& Weiss, A. A. (1983). Time Series Analysis of error-correcting models: Studies in Econometrics, Time Series, and Multivariate Statistics. New York: Academic Press: 255-278.

Gujarati, D. N. (2010). Basic Econometrics. New York: McGraw-Hill Inc.

Hamilton, J. D. (1990). Analysis of time series subject to changes in regime. Journal of Econometrics, 45, 39-70.

Harris, R. J. D. (1995). Using Cointegration Analysis in Econometric Modelling. Harvester Wheatsheaf, Prentice Hall.

Hendry, D. F. \& Juselius, K. (2000). Explaining cointegration analysis: Part I. Energy Journal, 21, 1-42.

Jacobsen, D. (2004,). What influences the growth of household debt? Economic Bulletin, 4, (3).

Johansen, S. (1991). Estimation and hypothesis testing of cointegrating vectors in Gaussian Vector Autoregressive Models. Econometrica, 59, 1551-1580.

Johansen, S. \& Juselius, K. (1990). Maximum Likelihood estimation and inference on cointegration with applications to the demand for money. Oxford Bulletin of Economics and Statistics, 52, 169-210.

Kaiser, H. F. (1974). An index of Factorial Simplicity. Psychometrika, 39, 34-36.

Kearns, A. \& Woods, M. (2006). The Concentration in property-related lending: a financial stability perspective. Financial Stability Report CBFSAI, 133-144.

Kennedy, P. (1996). A Guide to Econometrics. 3rd Edition. Massachusetts, Blackwell Publishers Inc. 
Keynes, J. M. (1936). The general theory of employment, interest and money. Macmillan Cambridge University Press, London.

Kim, Y. K. (2011). The macroeconomic implications of households' debt: An empirical analysis. Trinity College Department of Economics, Working Paper No. 11-03.

Kline, P. (1999). The Handbook of Psychological Testing (2nd Ed.). London: Routledge.

Kwiatkowski, D., Phillips, P. C. B., Schmidt, P. \& Shin, Y. (1992). Testing the null hypothesis of stationarity against the alternative of a unit root: How sure are we that time series have a unit root? Journal of Econometrics, 54, 159-178.

Laina, P. (2011). Dynamic Effects of total debt and GDP, A Time-Series Analysis of the United States. Masters' Dissertation, Department of Economics, Alto University.

Lauridsen, J. (1998). Spatial Cointegration Analysis in Econometric Modelling. Department of Statistics and Demography, Odense University. Campus survey 55 DK-5230 Odense M Available online at www.ou.dk/rrvf/statdem/lauriden.html (Accessed 14/7/2010).

Mason, J. W. \& Jayadev, A. (2012). Fisher dynamics in household debt: the case of the United States. 19292011.

Maysami, R. C. \& Koh, T. S. (2000). A vector error correction model of the Singapore stock market. International Review of Economics and Finance, 9, 79-96

Meng, S., Hoang, T. N. \& Siriwardana, M. (2011). The determinants of Australia household debt: a macro Level study. Business, economics and public policy working papers, 2011-2014.

Modigliani, F. (1986). Life cycle hypothesis, individual thrift and the wealth of nations. The American Economic Review, 76(3), 297-313.

Moroke, N.D. \& Mavetera, N. (2014). Exploratory Factor Analysis to investigate inter-relationships amongst serious crime in South Africa. European Journal of Social Sciences, 41(8).

Nelson, C. R. \& Plosser, C. I. (1982). Trends and random walks in macroeconomic time series: some evidence and implications. Journal of Monetary Economics, 10, 139-62.

Nwachukwu, T. E. \& Egwaikhide, F. O. (2007). An Error-Correction Model of the determinants of private saving in Nigeria. A Paper presented at the African Economic Society (AES) Conference, Cape Town, South Africa.

Obayelu A. E. \& Salau, A. S. (2010). Agricultural response to prices and exchange rate in Nigeria: Application of cointegration and vector error correction model. Journal of Agricultural Science, $1(2), 73-81$

Osterwald-Lenum, M. (1992). A Note with Quantiles of the asymptotic distribution of the maximum likelihood cointegration rank test statistic. Oxford Bulletin of Economics and Statistics, 54, 461472.

Phillips, A. W. H. (1954). Stabilization policy in a closed economy. Economic Journal, 64, 290-333.

Prinsloo, J. W. (2002). Household debt, wealth and saving. South African Reserve Bank Quarterly Bulletin, 226, 63-78.

Sargan J. D. (1964). Wages and Prices in the United Kingdom: A study in econometric methodology. PE Hart.

Sjö, B. (2008). Testing for unit roots and cointegration. Available at: http://www.iei.liu.se/nek/ekonometrisk-teori-7-5-hp-730a07/labbar/1.233753/dfdistab7b.pdf

Subhanij, T. (2007). Some lessons from Securitisation Crisis. Bangkok Post Business New, (13 July, 2007).

Thaicharoen, Y., Ariyapruchya, K. \& Chucherd, T. (2004). Rising Thai Household debt: assessing risk and policy implications. Bank of Thailand discussion paper, http://www.bot.or.th/BOTHomepage/DataBank/Econcond/seminar/yearly/9-14-2004-Eng-i12/paper1.pdf.

Toda, H. Y. \& Yamamoto, T. (1995). Statistical inference in vector autoregressions with possibly integrated processes. Journal of Econometrics, 66, 225-250.

Tudela, M. \& Young, G. (2005). The determinants of household debt and balance sheets in the United Kingdom. Bank of England Working Paper 266.

Verbeek, M. (2004). A Guide to Modern Econometrics. (2nd Ed). New York: John Wiley and Sons. 